\title{
Poverty Traps and Nonlinear Income Dynamics with Measurement Error and Individual Heterogeneity
}

\author{
Francisca Antman, Department of Economics, Stanford University \\ David J. McKenzie, Development Research Group, World Bank
}

\begin{abstract}
Theories of poverty traps stand in sharp contrast to the view that anybody can make it through hardwork and thrift. However, empirical detection of poverty traps is complicated by the lack of long panels, measurement error, and attrition. This paper shows how dynamic pseudo-panel methods can overcome these difficulties, allowing estimation of non-linear income dynamics and testing for the presence of poverty traps. The paper explicitly allows for individual heterogeneity in income dynamics, to account for the possibility that particular groups of individuals may face traps, even if the average individual does not. These methods are used to examine the evidence for a poverty trap in labor earnings, income, and expenditure in Mexico and are compared to panel data estimates from a short rotating panel. The results do find evidence of nonlinearities in household income dynamics, and demonstrate large bias in the panel data estimates. Nevertheless, even after allowing for heterogeneity and accounting for measurement error, we find no evidence of the existence of a poverty trap for any group in our sample.
\end{abstract}

JEL classification: O12, D31, C81

Keywords: nonlinear income dynamics, poverty traps, dynamic pseudo panel; measurement error.

World Bank Policy Research Working Paper 3764, November 2005

The Policy Research Working Paper Series disseminates the findings of work in progress to encourage the exchange of ideas about development issues. An objective of the series is to get the findings out quickly, even if the presentations are less than fully polished. The papers carry the names of the authors and should be cited accordingly. The findings, interpretations, and conclusions expressed in this paper are entirely those of the authors. They do not necessarily represent the view of the World Bank, its Executive Directors, or the countries they represent. Policy Research Working Papers are available online at http://econ.worldbank.org.

\footnotetext{
${ }^{*}$ Corresponding Author. E-mail: dmckenzie@worldbank.org; Address: Development Research Group, World Bank, MSN MC3-301, 1818 H Street N.W., Washington D.C. 20433; Fax: (202) 522-3518.
} 


\section{Introduction}

Does poverty beget poverty? The notion of a poverty trap, whereby current poverty is a direct cause of poverty in the future, provides a powerful explanation for the persistence of poverty and a rationale for numerous policy interventions. The theoretical literature has provided several plausible models which can give rise to poverty traps. ${ }^{1}$ A common feature of many theories of a poverty trap at the micro-level is the combination of borrowing constraints and an indivisible investment, leading to the existence of a critical threshold in assets, income, or expenditure, which a household is unable to surpass if forced below it. Examples include individuals who are too poor to purchase the minimum level of nutrients needed for productive work (Dasgupta and Ray, 1986), obtain a lumpy amount of education (Galor and Zeira, 1993), or buy physical capital needed for entrepreneurship (Banerjee and Newman, 1993). Even with convex technology, Mookherjee and Ray (2002) show that when employers or lenders have all the bargaining power in contracts with workers or borrowers, contractual distortions resulting from moral hazard can also give rise to poverty traps. $^{2}$

A sharp contrast to the poverty trap view of the world is the idea that "anybody can make it" through hardwork and thrift, which Ghatak, Morelli and Sjostrom (2001) term the American Dream effect. In their model, capital market imperfections may actually improve social welfare by providing incentives to work hard while young, in order to enjoy rents in old age. Bowles, Durlauf and Hoff (2004, p.1) summarize this view as saying that "initial poverty typically does not entrap; only those who don't make the effort remain in its clutches".

Despite the striking differences in policy implications, the empirical litera-

\footnotetext{
${ }^{1}$ See Bardhan, Bowles and Gintis (2000), Azariadis and Stachurski (2004) and Bowles, Durlauf and Hoff (2004) for recent summaries.

${ }^{2}$ The reason is that such contracts need to provide poor agents with rents as an incentive to exert effort. As agents become richer, these rents are progressively withdrawn, effectively creating 100-percent marginal tax on wealth accumulation by the poor, and hence causing the poor not to save. (Mookherjee and Ray, 2002).
} 
ture has found it hard to adjudicate between these two worldviews. One strand of the empirical literature has attempted to test particular theories of poverty traps. For example, Strauss and Thomas (1998) review studies which look for nonlinear relationships between health and productivity, and McKenzie and Woodruff (2003) test for non-convexities in returns to microenterprise investment. These studies generally have not found support for poverty traps caused by the particular mechanism being studied ${ }^{3}$, but leave open the question of whether poverty traps may still arise due to the non-studied processes.

A second strand of recent literature has therefore attempted to look directly at the dynamics of income, expenditure, or assets in order to test for nonconvexities and poverty traps. Lokshin and Ravallion (2004) use a six-year panel from Hungary and four-year panel from Russia to carry out nonlinear estimation of the relationship between current and lagged income. Almost one half of their sample has attrited by the end of the panel, and so they use a systems estimator which explicitly models attrition as a function of initial observed characteristics of the household. They do find the mapping from lagged income to current income to be nonlinear, but find no evidence of low-level threshold effects which would be associated with poverty traps. Jalan and Ravallion (2004) obtain similar findings using a six-year panel of income from four provinces in China.

Carter and Barrett (2005) criticize the use of short panels of income or expenditure to test for poverty traps by claiming that they are unable to distinguish between structural poverty and short-term transitory movements into and out of poverty. ${ }^{4}$ This can be exacerbated by measurement error, which can lead a household to be mis-classified as poor in one period and correctly classified as non-poor in the next. They further note that many theories of poverty traps are based on an asset threshold, and propose study of the dynamics of asset poverty. Such an approach is followed by Lybbert et al. (2004), who use 17

\footnotetext{
${ }^{3}$ However, see Dasgupta (1997) for a critique of empirical studies of the nutrition-based efficiency wage model.

${ }^{4}$ They note (p.2) that "with long enough panels, this limitation might be moot, but in the short term...panels with more than two or three observations in a span of a few years remain quite uncommon".
} 
years of retrospective livestock history to examine wealth dynamics in southern Ethiopia, finding some support for a poverty trap in livestock wealth. However, panel data on assets is rare in developing countries, especially outside of an agricultural context, and even when available, is likely to suffer from the same measurement error and attrition issues as data on income.

This paper proposes a dynamic pseudo-panel approach to the estimation of nonlinear income dynamics and uses this method to test for the presence of poverty traps in Mexican income and expenditure. ${ }^{5}$ The use of pseudo-panels can greatly mitigate the three major data issues facing the empirical study of poverty traps: a lack of long panels, attrition, and measurement error. A pseudo-panel tracks cohorts of individuals over repeated cross-sectional surveys (Deaton, 1985). Since such surveys are often available over longer time-periods than genuine panels, this approach can allow for the study of longer-term dynamics than is usually possible with panels. The Mexican Urban Labor Force Survey (ENEU) used here is a quarterly rotating panel available from 19872001. This enables us to use 58 quarters of data in the pseudo-panel estimation, compared to panels of only 5 quarters.

Non-random attrition is much less of a problem in pseudo-panels than in panels since a new sample of households is drawn in each period. In Antman and McKenzie (2005), we show that construction of a pseudo-panel eliminates the measurement error bias from dynamic linear models. This bias is found to be large: panel data estimation would suggest that one-third of the gap in income between two randomly selected households would close within one quarter, while pseudo-panel analysis shows only 1.2 percent of this gap would be eliminated. This paper extends the study of pseudo-panels to the non-linear dynamic models needed for the study of poverty traps. We employ the functional form of Lokshin and Ravallion (2004), in modelling income as a polynomial of lagged income.

\footnotetext{
${ }^{5}$ Only limited data on asset ownership, in the form of housing infrastructure, is available in our survey and so we do not examine asset dynamics here. Nevertheless, the methods proposed here could also be used to form pseudo-panel estimates of asset dynamics where such data are available.
} 
We show that measurement error does not affect the pseudo-panel estimates of the slope coefficients in this polynomial, enabling one to determine whether or not the income mapping is non-convex. However, the second and higher-order moments of the measurement error will have an effect on the intercept term in this polynomial, and we derive a correction factor for this term.

A further innovation in our approach is to explicitly allow for individual heterogeneity in modelling income dynamics and testing for poverty traps. This enables us to determine whether there are particular groups of individuals who face traps, even if the average individual in society does not. For example, an individual with higher ability or with a better intrinsic health endowment may be able to produce more than an individual with the same lagged income who has lower ability or intrinsic health. Figure 1 illustrates this case, plotting three non-convex curves mapping lagged income to current income. Individuals depicted by Curve A have non-linear income dynamics, but do not face a poverty trap as the curve lies entirely above the 45 degree line. Individuals with income dynamics following Curve $\mathrm{C}$ are always in a poverty trap. Curve B is the classic poverty trap case, where there is a threshold level of income, $Y_{u}$, below which individuals are in a trap. Allowance for individual heterogeneity enables us to check whether some individuals are in case $\mathrm{B}$ or $\mathrm{C}$, even if the average individual has dynamics given by Curve A.

We begin by checking for the presence of poverty traps with the short panels of household labor income. No individuals are found to have income dynamics which would lead to a poverty trap, and indeed the results indicate high mobility of incomes. However, such high mobility is likely to be the result of measurement error, and we proceed to pseudo-panel estimation. The pseudo-panel estimates do indeed show a greater influence for past income on current income than the panel data results. However, although the nonlinear lagged income terms are statistically significant, they are small in magnitude, and the income mapping is close to linear over the fitted income range. While measurement error appears to have large effects on estimation of the slope coefficients in this mapping, correcting for the influence of higher order moments of the measurement error 
on the intercept term only marginally changes the estimated income mapping. Based on this pseudo-panel estimation, we check whether the income dynamics for the average individual in any of our cohorts give rise to a poverty trap and find they do not. Thus, while income mobility is low in Mexico, there is no evidence for a poverty trap in income. These results continue to hold once we allow for slope parameter heterogeneity across education groups, and when we estimate dynamics for full household income and expenditure using an alternative data set.

The remainder of the paper is organized as follows: Section 2 describes the econometric method used to estimate nonlinear income dynamics and detect poverty traps with panels and pseudo-panels; Section 3 describes the ENEU data; Section 4 provides the results; Section 5 examines the robustness of our results to slope-parameter heterogeneity and to the use of alternative measures of household resources than labor earnings; and Section 6 concludes.

\section{Econometric Method}

\subsection{Panel Data without Measurement Error}

We follow Jalan and Ravallion (2004) and Lokshin and Ravallion (2004) in allowing for non-linear income dynamics in the form of a cubic function of the lagged dependent variable, and in allowing for individual heterogeneity through the inclusion of unobserved individual effects, $\alpha_{i}$. We discuss below extension to higher-order polynomials. The data generating process for the true income $Y_{i, t}^{*}$ of household $i$ in time period $t$ is assumed to be:

$$
Y_{i, t}^{*}=\beta_{1} Y_{i, t-1}^{*}+\beta_{2}\left(Y_{i, t-1}^{*}\right)^{2}+\beta_{3}\left(Y_{i, t-1}^{*}\right)^{3}+\alpha_{i}+u_{i, t}
$$

If the true values of income are observed and the $u_{i, t}$ are serially uncorrelated, then equation (1) can be estimated via the GMM method of Arellano and Bond (1991). This is the method used by Jalan and Ravallion (2004), who difference (1) and then use $Y_{i, t-2}^{*},\left(Y_{i, t-2}^{*}\right)^{2}$ and $\left(Y_{i, t-2}^{*}\right)^{3}$ as instruments for $\Delta Y_{i, t-1}^{*}$, 
$\Delta\left(Y_{i, t-1}^{*}\right)^{2}$ and $\Delta\left(Y_{i, t-1}^{*}\right)^{3}$.

With no measurement error in income, one can then obtain consistent estimates $\widehat{\beta}_{1}, \widehat{\beta}_{2}$ and $\widehat{\beta}_{3}$. These parameter estimates enable us to determine whether there is a non-convexity in the income mapping, but are not in themselves sufficient to determine whether or not individuals face a poverty trap. If the income mapping always lies above the 45 degree line, then a non-convex income mapping results in different rates of income growth at different levels of income, but in no poverty trap. Curve $\mathrm{A}$ in Figure 1 illustrates this possibility. For a poverty trap to exist, it must be either the case that the income mapping always lies below the 45 degree line (as in Curve $\mathrm{C}$ of Figure 1), or that the income mapping crosses the 45 degree line from below. Curve B in Figure 1 illustrates this case.

For a given income mapping $Y_{i, t}^{*}=g_{i}\left(Y_{i, t-1}^{*}\right)$, we can then see that a necessary and sufficient condition for a poverty trap of the type given by Curve B in Figure 1 is that

$$
\left.g_{i}^{\prime}\left(Y_{i, t-1}^{*}\right)\right|_{Y_{i, t}^{*}=Y_{i, t-1}^{*}}>1
$$

Note that the function $g$ depends on $i$ due to the presence of the individual effects $\alpha_{i}$. Based on equation (1) and the parameter estimates $\widehat{\beta}_{1}, \widehat{\beta}_{2}$ and $\widehat{\beta}_{3}$, we estimate $\alpha_{i}$ by

$$
\widehat{\alpha}_{i}=\bar{Y}_{i}-\widehat{\beta}_{1} \bar{Y}_{i,-1}-\widehat{\beta}_{2} \bar{Y}_{i,-1}^{2}-\beta_{3} \bar{Y}_{i,-1}^{3}
$$

where

$$
\begin{aligned}
\bar{Y}_{i} & =\frac{1}{T-1} \sum_{t=2}^{T} Y_{i, t}^{*} \\
\text { and } \bar{Y}_{i,-1}^{s} & =\frac{1}{T-1} \sum_{t=1}^{T-1}\left[\left(Y_{i, t}^{*}\right)^{s}\right] \text { for } \mathrm{s}=1,2,3
\end{aligned}
$$

Then for our cubic specification, the condition in (2) amounts to evaluating whether 


$$
\widehat{\beta}_{1}+2 \widehat{\beta}_{2} Y_{i, t-1}^{*}+3 \widehat{\beta}_{3}\left(Y_{i, t-1}^{*}\right)^{2}>1
$$

evaluated at the $Y_{i, t-1}^{*}$ for which $Y_{i, t}^{*}=Y_{i, t-1}^{*}$. i.e. at the fixed point of the estimated mapping $g_{i}($.$) . There may be particular periods when this occurs due$ to a large shock, $u_{i, t}$, but we want to know if this occurs for the expected $u_{i, t}$ of zero. So we need to evaluate equation (4) at the $Y_{i, t}^{*}$ which solves:

$$
Y_{i, t}^{*}=\widehat{\beta}_{1} Y_{i, t}^{*}+\widehat{\beta}_{2}\left(Y_{i, t}^{*}\right)^{2}+\widehat{\beta}_{3}\left(Y_{i, t}^{*}\right)^{3}+\widehat{\alpha}_{i}
$$

Equation (5) can then be solved to obtain the crossing point(s) $Y_{i, t}^{*}$ of each individual's income mapping. The condition in equation (4) can then be evaluated for each individual at their specific crossing point(s) to determine whether any individuals are estimated to face a poverty trap. As discussed in the introduction, allowing for individual heterogeneity in a number of the theoretical models of poverty traps may result in some individuals facing traps and not others, and this methodology allows us to incorporate this possibility. In addition, one can determine whether the average individual income dynamics give rise to a poverty trap by evaluating (4) at the crossing point determined by the average $\widehat{\alpha}_{i}$.

\subsection{Panel Data with Measurement Error}

In practice one does not observe the true income measure $Y_{i, t}^{*}$, but rather observes $Y_{i, t}$, whereby:

$$
Y_{i, t}=Y_{i, t}^{*}+\varepsilon_{i, t}
$$

Here the measurement error $\varepsilon_{i, t}$ is assumed to be mean zero and independently distributed across individuals with $E\left(\varepsilon_{i, t}^{2}\right)=\sigma_{\varepsilon}^{2}$. The data generating process of the observed data is then: 


$$
Y_{i, t}=\beta_{1} Y_{i, t-1}+\beta_{2} Y_{i, t-1}^{2}+\beta_{3} Y_{i, t-1}^{3}+\alpha_{i}+\eta_{i, t}
$$

where $\eta_{i, t}=u_{i, t}+\varepsilon_{i, t}$

$$
\begin{aligned}
& -\left(\beta_{1}+2 \beta_{2} Y_{i, t-1}+3 \beta_{3} Y_{i, t-1}^{2}\right) \varepsilon_{i, t-1} \\
& +\left(\beta_{2}+3 \beta_{3} Y_{i, t-1}\right) \varepsilon_{i, t-1}^{2} \\
& -\beta_{3} \varepsilon_{i, t-1}^{3}
\end{aligned}
$$

As is well known, in the linear regression model with no individual heterogeneity, if the measurement errors are serially uncorrelated, the OLS estimate of $\beta_{1}$ will be biased towards zero, leading one to conclude that there is less persistence in the income process than is truly the case. The Arellano-Bond instrumental variable approach will also be inconsistent with measurement error except in special cases. In the linear model, if there is no autocorrelation in the measurement error, using $Y_{i, t-3}$ in place of $Y_{i, t-2}$ as an instrument will give consistency. ${ }^{6}$ However, in the quadratic and cubic cases earlier lags will still result in inconsistency, and even in the linear case, autocorrelation in the measurement error will rule out the use of earlier lags as instruments. Data from validation studies on income in the U.S. does indeed suggest positive autocorrelation in the measurement error (Bound and Krueger, 1991). As a result, in the presence of measurement error, these panel data estimates will be inconsistent and therefore not enable one to determine whether there are non-convexities in the income mapping or to detect the presence of poverty traps.

\subsection{Estimation of non-linear income dynamics with pseudo- panels}

We propose using pseudo-panel methods to consistently estimate the income mapping. A pseudo-panel tracks cohorts of individuals over repeated cross-

\footnotetext{
${ }^{6}$ To see this, note that the error term in the differenced equation contains $\Delta \varepsilon_{i, t}-\beta_{1} \Delta \varepsilon_{i, t-1}$. As a result, $Y_{i, t-2}$ will be correlated with the error term through $\varepsilon_{i, t-2}$. If the $\varepsilon_{i, t}$ are serially uncorrelated, then $E\left(Y_{i, t-3} \varepsilon_{i, t-2}\right)=0$ and $Y_{i, t-3}$ will serve as an instrument.
} 
sectional surveys.. Moffitt (1993), Collado (1997), McKenzie (2004) and Verbeek and Vella (forthcoming) discuss conditions under which one can consistently estimate linear dynamic models with pseudo-panels. Our aim here is to show that these methods can also deal with the measurement error problems facing panel data models, and to provide details for the estimation of non-linear income dynamics.

Begin by taking cohort averages of equation (7) over the $n_{c}$ individuals observed in cohort $c$ at time $t$ :

$$
\begin{aligned}
\bar{Y}_{c(t), t}= & \beta_{1} \bar{Y}_{c(t), t-1}+\beta_{2}\left(\frac{1}{n_{c}} \sum_{i=1}^{n_{c}}\left(Y_{i(t), t-1}^{2}\right)\right) \\
& +\beta_{3}\left(\frac{1}{n_{c}} \sum_{i=1}^{n_{c}}\left(Y_{i(t), t-1}^{3}\right)\right)+\alpha_{c(t)}+\bar{\eta}_{c(t), t}
\end{aligned}
$$

where $\bar{Y}_{c(t), t}=\left(1 / n_{c}\right) \sum_{i=1}^{n_{c}} Y_{i(t), t}$ denotes the sample mean of $Y$ over the individuals in cohort $c$ observed at time $t$. With repeated cross-sections, different individuals are observed each time period. As a result, the lagged mean $\bar{Y}_{c(t), t-1}$, representing the mean income in period $t-1$ of the individuals in cohort $c$ observed at time $t$, (denoted here $c(t)$ ) is not observed. Likewise the mean of the lagged square and mean of the lagged cubic are also unobserved. Therefore we replace the unobserved terms with the sample means over the individuals who are observed at time $t-1$, leading to the following regression for cohorts $c=1,2, \ldots, C$ and time periods $t=2, \ldots, T$ :

$$
\begin{aligned}
\bar{Y}_{c(t), t}= & \beta_{1} \bar{Y}_{c(t-1), t-1}+\beta_{2}\left(\frac{1}{n_{c}} \sum_{i=1}^{n_{c}}\left(Y_{i(t-1), t-1}^{2}\right)\right) \\
& +\beta_{3}\left(\frac{1}{n_{c}} \sum_{i=1}^{n_{c}}\left(Y_{i(t-1), t-1}^{3}\right)\right) \\
& +\alpha_{c(t)}+\bar{\eta}_{c(t), t}+\lambda_{c(t), t}
\end{aligned}
$$

where 


$$
\begin{aligned}
\lambda_{c(t), t}= & \beta_{1}\left(\bar{Y}_{c(t), t-1}-\bar{Y}_{c(t-1), t-1}\right)+ \\
& \beta_{2}\left(\frac{1}{n_{c}} \sum_{i=1}^{n_{c}}\left(Y_{i(t), t-1}^{2}\right)-\frac{1}{n_{c}} \sum_{i=1}^{n_{c}}\left(Y_{i(t-1), t-1}^{2}\right)\right) \\
& +\beta_{3}\left(\frac{1}{n_{c}} \sum_{i=1}^{n_{c}}\left(Y_{i(t), t-1}^{3}\right)-\frac{1}{n_{c}} \sum_{i=1}^{n_{c}}\left(Y_{i(t-1), t-1}^{3}\right)\right)
\end{aligned}
$$

As shown in the general model of McKenzie (2004), as the number of individuals in each cohort becomes large, $\lambda_{c(t), t}$ converges to zero, and hence we will ignore this term in what follows.

Let us first consider the case of linear dynamics, setting $\beta_{2}$ and $\beta_{3}$ to zero. Then equation (10) becomes:

$$
\begin{aligned}
\bar{Y}_{c(t), t}= & \beta_{1} \bar{Y}_{c(t-1), t-1} \\
& +\alpha_{c(t)}+\bar{u}_{c(t), t} \\
& +\bar{\varepsilon}_{c(t), t}-\beta_{1} \bar{\varepsilon}_{c(t), t-1}
\end{aligned}
$$

We have that as the number of individuals in each cohort gets large, $n_{c} \rightarrow \infty$,

$$
\bar{\varepsilon}_{c(t), t}=\frac{1}{n_{c}} \sum_{i=1}^{n_{c}} \varepsilon_{i(t), t} \stackrel{p}{\rightarrow} E\left(\varepsilon_{i(t), t}\right)=0
$$

That is, since the construction of the pseudo-panel involves averaging over the observations in a cohort, we average out the individual measurement errors. As a result, with sufficient observations per cohort, the measurement errors do not affect the consistency of estimates from equation (12). The parameter $\beta_{1}$ and the cohort-specific effects $\alpha_{c}$ can then be estimated via OLS on the cohort average equation (12). This will be consistent as the number of individuals per cohort gets large. ${ }^{7}$

\footnotetext{
${ }^{7}$ Alternatively one can use lagged cohort means as instruments, as in Collado (1997). McKenzie (2004) discusses the practical and theoretical issues involved in choosing between the OLS and IV approaches to estimating linear dynamic models on cohort averages.
} 
In the more general case of non-linear income dynamics, OLS estimation of the cohort average equation (10) will still lead to consistent estimates of $\beta_{1}, \beta_{2}$ and $\beta_{3}$, allowing one to determine if there are non-convexities in the income dynamics. However, the OLS estimates of the cohort-specific effects $\alpha_{c}$ will be biased. To correct for this bias we need to impose further restrictions on the form of the measurement error. In particular, we assume that:

i) The measurement errors are symmetric, so that $E\left(\varepsilon_{i, t}^{3}\right)=0$

ii) The measurement errors are stationary, so that $E\left(\varepsilon_{i, t}^{2}\right)=\sigma_{\varepsilon}^{2}$ is constant over time. We can allow the variance of the measurement errors to differ across cohorts.

iii) The measurement errors are independent of the true values within a cohort, so $\varepsilon_{i, t}$ is independent of $Y_{i, t}^{*}$ for all $i$ in a given cohort $c$.

Under these assumptions, based on equations (7) and (8), one can easily show that as $n_{c} \rightarrow \infty$, the OLS estimate of $\alpha_{c}, \widehat{\alpha}_{c}$ converges as follows:

$$
\widehat{\alpha}_{c} \stackrel{p}{\rightarrow} \alpha_{c}-\beta_{2} \sigma_{\varepsilon}^{2}-3 \beta_{3} E_{c}\left(Y_{i, t-1}^{*}\right) \sigma_{\varepsilon}^{2}
$$

where $E_{c}\left(Y_{i, t-1}^{*}\right)$ is the cross-sectional mean in income for individuals in cohort $c$ at time $t-1$. Under assumptions (ii) and (iii) we have that the cross-sectional variance of income is:

$$
\operatorname{Var}\left(Y_{i, t}\right)=\operatorname{Var}\left(Y_{i, t}^{*}\right)+\sigma_{\varepsilon}^{2}
$$

Rearranging then gives:

$$
\sigma_{\varepsilon}^{2}=\operatorname{Var}\left(Y_{i, t}\right)\left[1-\frac{\operatorname{Var}\left(Y_{i, t}^{*}\right)}{\operatorname{Var}\left(Y_{i, t}\right)}\right]
$$

Equation (15) can then be used to obtain an estimate, $\widehat{\sigma}_{\varepsilon}^{2}$ of $\sigma_{\varepsilon}^{2}$ based on the sample cross-sectional variance of observed incomes, and on an estimate of $\theta=\operatorname{Var}\left(Y_{i, t}^{*}\right) / \operatorname{Var}\left(Y_{i, t}\right)$. Proxies for this reliability ratio can be obtained from validation studies (see Bound, Brown and Mathiowetz, 2001). We calculate $\widehat{\sigma}_{\varepsilon}^{2}$ 
for two different values of $\theta, 0.5$ and 0.8 , which span the main range of estimates found in U.S. validation studies. Under the assumption that the measurement error is mean zero, we can then estimate $E_{c}\left(Y_{i, t-1}^{*}\right)$ with the sample crosssectional mean $\bar{Y}_{c(t-1), t-1}$, and therefore estimate $\alpha_{c}$ by:

$$
\widetilde{\alpha}_{c}=\widehat{\alpha}_{c}+\widehat{\beta}_{2} \widehat{\sigma}_{\varepsilon}^{2}+3 \widehat{\beta}_{3} \bar{Y}_{c(t-1), t-1} \widehat{\sigma}_{\varepsilon}^{2}
$$

Under assumptions (i)-(iii), as the number of individuals in each cohort goes to infinity, $\widetilde{\alpha}_{c}$ will provide a consistent estimate of the cohort effect $\alpha_{c}$.

Based on these estimates, one can then go back to equations (4) and (5) at the cohort mean level, in order to determine whether any specific cohort faces a poverty trap by determining the slope of the estimated cubic income mapping at the income level(s) at which the 45 degree line is crossed.

Note that at no stage did we impose any restrictions on the serial correlation properties of the measurement error. Since different individuals are observed in each time period, we can allow for arbitrary patterns of correlation over time in the measurement errors provided that we assume cross-sectional independence of the measurement errors across individuals. ${ }^{8}$

Secondly, note that extension of this method to higher order polynomials in the lagged dependent variable will require imposing more structure on the distribution of the measurement error term in order to estimate $\alpha_{c}$. One can still obtain consistent estimates of the slope parameters $\beta$ without these additional assumptions, but the corrections for measurement error needed to estimate $\alpha_{c}$ will involve assumptions on higher-order moments of the $\varepsilon_{i, t}$ 's. For example, with a quartic, the correction requires an estimate of the fourth moment of the measurement error, along with an estimate of the cross-sectional variance of true income.

In practice this methodology offers several advantages over using genuine panel data. In many situations genuine panel data are not available, or are available for only short periods, whereas much larger samples over longer periods

\footnotetext{
${ }^{8}$ More generally, we can allow for a fixed component in the measurement error term for each cohort, which gets captured in the cohort-specific effect $\alpha_{c}$.
} 
of time are available with cross-sectional surveys. Secondly, an important issue with the examination of income dynamics with genuine panel data is the extent to which non-random attrition biases the results. In particular, one may be concerned that individuals whose incomes suffer large falls or large increases may be much more likely to move houses and leave the sample. While there are structural approaches one can take to attempt to account for attrition (e.g. see

Lokshin and Ravallion (2004)), the use of pseudo-panel data is not subject to these same attrition issues. Thirdly, the use of different individuals each period allows for very general forms of serial correlation in the individual measurement errors. The main disadvantage of the use of pseudo-panels instead of genuine panels for the purpose of identifying poverty traps is that while we can still allow for heterogeneity of the intercept at the individual level, we can only evaluate the condition in equation (4) for each cohort at the crossing point(s) determined by the cohort average intercept, rather than at a separate intercept for each individual. This enables us to determine whether the income dynamics of the average individual within a particular cohort give rise to a poverty trap.

\section{Data}

The data come from Mexico's Encuesta Nacional de Empleo Urbano (ENEU), a quarterly urban employment survey collected by Mexico's Instituto Nacional de Estadística, Geografía e Informática (INEGI) over the period from the first quarter of 1987 to the second quarter of $2001 .^{9}$ Over this period the ENEU expanded coverage from 16 cities in 1987 to 34 cities by the end of 1992 and 44 cities by the second quarter of 2001 . We include all 39 cities present by the end of 1994, although our results are robust to restricting the sample to just the 16 cities present in all years. The survey is designed as a rotating panel, with households followed for five consecutive quarters. In addition to information on household demographics and education of all members, each individual aged 12 and above in the household is asked detailed questions about employment and

\footnotetext{
${ }^{9}$ The survey was changed after this date, preventing the use of more recent data.
} 
labor income. As is common in many such surveys, the survey tracks a dwelling unit, so that individuals which move houses attrit from the panel.

We examine income dynamics at the household level and test whether poverty traps exist for households. The ENEU only collects data on labor earnings for each household member in their principal occupation. We add this over household members and deflate by the Consumer Price Index for the relevant quarter from the Bank of Mexico to obtain real household labor earnings. To focus only on households for whom labor earnings are likely to be a main source of income, we restrict our sample to households with heads aged 25 to 49 years old. On average two percent of the observations have household labor income of zero. Using data from the ENIGH income and expenditure survey, which does include non-labor sources of income, we calculate that labor income represents 95 percent of total monetary income for urban households with heads in the 25-49 year old age range. In Section 5 we examine the robustness of our results to using full income and expenditure from the ENIGH.

After imposing these restrictions on the age of the household head and dropping missing values, we have 54 five-quarter panels, beginning with the panel of 3,930 households which were sampled from the first quarter of 1987 through to the first quarter of 1988 , and ending with the panel of 11,158 households sampled from the second quarter of 2000 through to the second quarter of 2001. This gives a total sample of 402,052 households. Ten percent of households are observed for only one quarter, while approximately 65 percent can be followed for all five quarters. For our panel data analysis we use unbalanced panels, resulting in 1,671,530 household-quarter observations in all.

Pseudo-panels are constructed on the basis of five year birth intervals of the household head interacted with three education levels (primary schooling or less, 7 to 12 years education, and more than 12 years education). For example, all household heads born between 1960 and 1964 with primary schooling or less would form one cohort. The household head is defined as the person recognized as the head by the other household members and is generally male. A potential concern with the panel data is that households who fall into or escape out of 
poverty may be the most likely to move, and therefore attrit from the panel. In order to ensure that the pseudo-panel does not suffer from the same problem, we construct our pseudo-panel using only the households who are in their first wave of the interview. As a result, we use just over 20 percent of the households available in any given cross-section, since the remaining households are those which are being re-interviewed. We restrict the sample further to cohorts with more than 100 observations in a given wave in order to be able to apply the asymptotic theory developed above which relies on a large number of observations per cohort. Approximately 9 percent of cohort-period observations have fewer than 100 households, and including these additional observations does not qualitatively affect our results. After these restrictions, we are left with a pseudo-panel over 58 quarters with 842 cohort-quarter observations.

\section{Results}

In order to get a sense of the relationship between income and lagged income over time, we begin with a locally weighted regression between household income and the quarterly lag of household income in the panel. ${ }^{10}$ Figure 2 shows the estimated relationship. Current income is seen to be an increasing function of lagged income, with the curve intersecting the 45 degree line only once, from above. Therefore, equation (2) does not hold, as the derivative of the curve is clearly less than unity at the intersection point, and thus there is no evidence of a poverty trap.

However, as argued above, it is important to take individual heterogeneity into account. Figure 3 shows the results from the panel data using the Arellano-Bond (1991) instrumental variables specification. This differences the data and uses lagged income as an instrument for the first difference of lagged income. Curves are then plotted for the average individual effect. The cubic and quadratic curves are now highly linear in shape, and all three curves show

\footnotetext{
${ }^{10}$ See Knieser and $\mathrm{Li}(2002)$ for discussion of estimation of local regressions with dynamic data.
} 
almost no relationship between current income and lagged income, after conditioning on individual effects. In Table 1 we then examine whether equation (2) holds for particular individuals, even if it doesn't hold for the average individual. For each of the linear, quadratic, and cubic specifications, we use equation (3) to estimate $\alpha_{i}$ for each individual, and then following equations (4) and (5), we evaluate the derivative of the estimated curve for each individual at the income level(s) where the curve crosses the 45 degree line. For the linear model there is only one crossing point, the quadratic model is evaluated at the two roots, and the cubic at the three roots. We report the derivative at the minimum, 25th, 50 th, 75 th, and maximum values of the distribution of estimated $\alpha_{i}$ 's.

Of course the derivative is constant for the linear model, and is estimated to be only 0.019 , well below one. The estimated quadratic crosses the 45 degree line twice: once for highly negative income, and once for a positive value of income. The derivatives at the crossing point for positive incomes range from -0.005 to 0.034 , and are again much less than one. The cubic model has one negative, and two positive crossing points. The derivative at the crossing point with the lower level of positive income ranges from -0.048 to 0.049 . While the derivative at the second positive crossing point is greater than unity (between 3.0 and 3.6), this crossing point occurs at a very high level of income, beyond the income range of the data. Hence within the observed range of positive incomes, all three panel data specifications show a derivative at the crossing point which is very close to zero. This certainly does not provide support for a poverty trap, but instead shows a very fast rate of conditional convergence of incomes. However, as shown in Antman and McKenzie (2005), this instrumentation approach will always give this result for the linear model when there is measurement error, regardless of the true shape of the linear dynamics. We therefore proceed to pseudo-panel estimation, which averages out the measurement error and gives consistent slope parameter estimates.

Figure 4 illustrates the importance of allowing for individual heterogeneity in the dynamics. The curve for the quadratic model when we assume a common intercept for all cohorts lies right on top of the 45 degree line, suggesting 
a one-to-one relationship between income and lagged income. However, once we allow for heterogeneity in the individual intercepts, the slope of the curve flattens. Plotting the curve for the average cohort intercept, we see that the curve crosses the 45 degree line from above, so again there is no poverty trap for the average cohort. Table 2 shows that when we examine this derivative across the distribution of cohort intercepts, it ranges from 0.774 to 0.790 , and is thus always less than unity.

Figure 5 compares the panel and pseudo-panel estimates of the linear dynamic model. The pseudo-panel results show much lower mobility of incomes than the genuine panel would suggest, but still cross the 45 degree line from above. The top of Table 2 shows that the derivative for the pseudo-panel is 0.730 , less than unity. In addition, it shows that the curve always crosses the 45 degree line at a positive level of income, so no cohorts have income mappings which lie entirely below the 45 degree line (as in Case C in Figure 1).

Figures 6 and 7 compare the panel and pseudo-panel curves for the quadratic and cubic models respectively, again plotting the curves at the average of the estimated cohort-specific intercepts. A second pseudo-panel curve is plotted after making the correction for the impact of higher order moments of the measurement error on the estimated cohort intercepts, using the procedure outlined in equations (15) and (16), assuming a reliability ratio of 0.5 . The coefficients on the quadratic and cubic terms are statistically significant at all conventional levels, providing evidence of some non-linearity in the income mapping. However, the coefficients are small in magnitude, so that the fitted curves appear close to linear over the observed sample range. As with the linear model, the quadratic and cubic pseudo-panel curves are steeper than the panel curves, suggesting that measurement error is causing one to overestimate the degree of mobility in panels, and make one less likely to detect poverty traps. However, the correction for the impact of higher-order moments of the measurement error has little visual impact, which is likely to be a result of the estimated curves being close to linear over the range of observed data.

The second and third parts of Table 2 compare the estimated derivatives of 
the quadratic and cubic model with and without this correction for the higherorder moment impacts of measurement error. Results are presented for reliability ratios of 0.5 and 0.8 . As with the genuine panel model, the pseudo-panel quadratic model only crosses the 45 degree line once in the range of positive incomes. The estimated derivative at the crossing point ranges from 0.774 to 0.790 without the additional measurement error correction. Making this correction only results in changes of 0.001 or less in the estimated derivatives. The cubic model again has two positive roots, with one root having a large derivative but being at high levels of income beyond the range observed in the data. The derivative at the crossing point within the range of observed income levels ranges from 0.796 to 0.902 without the additional measurement error correction, and from 0.793 to 0.897 with this correction. The derivatives therefore do vary, showing the importance of allowing for heterogeneity. The derivatives also vary somewhat from the linear model derivative of 0.730 , showing some evidence for non-linearities in income dynamics. Nevertheless, all of the derivatives at the crossing points are less than unity, and hence do not support the existence of a poverty trap.

Overall these results therefore show that the panel data estimates appear to greatly understate the slopes of the income dynamic curves at the crossing points, thereby making it unlikely that they will detect derivatives greater than one, and hence poverty traps. Nevertheless, although the pseudo-panel estimates show less mobility in incomes, they do not provide any evidence of poverty traps in income: all of the derivatives are less than unity. While the quadratic and cubic terms are statistically significant in the pseudo-panel model, providing evidence for non-linear income dynamics, these non-linearities are not very large in magnitude over the observed income range, and do not give rise to poverty traps. 


\section{Robustness}

\subsection{Slope parameter heterogeneity}

Our analysis has allowed for heterogeneity in the intercept term in the equation mapping lagged income to current income. It is also of interest to examine whether the shape of the income mapping also exhibits heterogeneity, and if so, to determine whether allowing for heterogeneity in the slope parameters will reveal evidence of a poverty trap. One problem with this approach is that allowing for more heterogeneity results in fewer observations being available to estimate each curve. We therefore chose to only allow for limited heterogeneity in the income mapping, letting the parameters $\beta_{1}, \beta_{2}$, and $\beta_{3}$ in equation (10) differ according to three levels of education of the household head (0-6 years, 712 years, and 13 or more years). This allows for the possibility that individuals with higher education may be better able to overcome barriers to investment at low income levels, possibly by substituting skills for physical capital, or by being better able to access credit markets.

Figure 8 plots the estimated curves for the three education groups, at the average level of the cohort-specific intercepts. We do indeed see heterogeneity in income dynamics by education level. The income mapping is steeper for higher education levels, indicating more rapid income growth, and the point of intersection with the 45 degree line lies at a higher level of income. As a result, individuals with high education and low income will experience faster income growth than individuals with the same income and lower education. Nevertheless, one still sees that each of the three curves crosses the 45 degree line from above, so that there is no poverty trap in incomes, even after allowing for slope heterogeneity in dynamics across education groups. The derivatives

evaluated at the intersection with the 45 degree line are all below unity, ranging from 0.77 at a crossing point of 5,330 for the lowest education group to 0.81 at an income level of 7,584 for the mid-level group and 0.87 at a crossing point of approximately 17,944 for the highest education group. 


\subsection{Beyond Labor Income}

The above results find no evidence of poverty traps in Mexican labor income. One potential concern is that some of the households with very low or zero labor income could be non-poor due to other sources of income, such as autoconsumption, transfers, rent and interest. As these households are not poor, we would not expect to find them in a poverty trap. However, their inclusion among other households with similar labor income levels who rely much more on labor income in the estimation of income dynamics is likely to reduce the chance of detecting poverty traps for this latter group.

We therefore examine the robustness of our results to the use of more comprehensive measures of household welfare. We use data from Mexico's National Income and Expenditure Survey, the Encuesta Nacional de Ingresos y Gastos de los Hogares (ENIGH). This survey has been taken biannually since 1992, and we use the six rounds from 1992-2002. ${ }^{11}$ To allow direct comparison with the urban employment survey, we use only data from cities of population 100,000 and above. As with the ENEU data, we restrict our analysis to households with heads aged 25 to 49 , and define cohorts based on five year birth intervals of the household head within three education groups. This results in a sample size of between 3,000 and 4,000 households in each round. Further restricting the number of observations per cohort in a round to be at least 100 results in a pseudo-panel of 19 cohorts observed over 6 time periods. ${ }^{12}$

We consider four measures of household welfare. The first measure is total household labor income from the principle occupation of each member, which corresponds to the measure we have used in the ENEU. The second measure is total monetary income of the household, which includes household income from

\footnotetext{
${ }^{11}$ Earlier rounds of this survey were also conducted in 1989 and 1984. The inclusion of these surveys would require estimating income dynamics over unequally-spaced time periods. While in principal the methods of McKenzie (2001) could be extended to cover the measurement error case, we choose to focus on the equally-spaced surveys for this paper.

${ }^{12}$ There are 82 cohort-wave observations, since some cohorts are not observed in every round, either due to insufficient observations, or due to the cohort being out of the 25-49 year age range for the household head.
} 
pensions, government transfer programs, rent, interest, remittances, and other monetary sources. The third measure, which we will call full income, adds the value of home-produced consumption, or auto-consumption, to monetary income. The final measure is total expenditure, which includes both monetary expenditure and the value of autoconsumption. The correlation between household labor income and total household monetary income averages 0.91 across the six surveys for urban households with heads in the age range 25-49. We should therefore expect similar results for these two measures. The correlation with full income is not much less, at 0.87 , while the correlation with total expenditure is 0.60 .

Figure 9 plots the fitted cubic income mappings for these four measures of household welfare. The curves are plotted at the average of the cohort specific intercepts, with a measurement error correction made as in equation (16) under the assumption that the reliability ratio is 0.5 . First, we note that shape of the estimated curve for labor income is very similar to that from the ENEU, seen in Figure 7. Secondly, total monetary income of the household has very similar income dynamics as labor income, showing that the omission of secondary job and non-labor earnings does not appear to have a sizeable impact on the estimated dynamics. However, thirdly, we note that the shape of full household income, which includes the value of home-produced goods, and the shape of the expenditure relationship do exhibit more curvature than labor earnings. Nevertheless, most importantly we see that all four measures of household welfare have mappings which cross the 45 degree line from above, hence showing that our finding of no evidence for poverty traps extends to these other measures.

\section{Conclusion}

This paper has shown how pseudo-panel methods can be used to investigate non-linear income dynamics in the presence of measurement error and individual heterogeneity. Panel data estimates suggested that income was very mobile, conditional on individual fixed effects, and that no individuals have income 
dynamics which could give rise to a poverty trap. Pseudo-panel analysis reveals more persistence in labor earnings, suggesting that measurement error is rather large in the panel data. Nevertheless, although we find some evidence of non-linearities in income dynamics, we estimate that the mapping from lagged income to current income always crosses the 45 degree line with a derivative less than unity. Hence, there is no evidence for a poverty trap in labor income. This result is robust to allowing different education groups to exhibit different income dynamics, and to using full income or expenditure in place of labor earnings.

In related work, Antman and McKenzie (2005) show that absolute mobility in Mexico is very low, suggesting that the high level of cross-sectional inequality in incomes will persist over time. Thus although the lack of a poverty trap suggests that poor individuals can experience income growth little by little over time, and not be trapped below some threshold level, this will be a rather slow process. The "Mexican dream" may therefore take a long time to be realized.

\section{References:}

Antman, F. and D. McKenzie (2005) "Earnings Mobility and Measurement Error: A Pseudo-Panel Approach", Mimeo. The World Bank and Stanford University.

Arellano, M. and S. Bond (1991) "Some tests of specification for panel data: Monte Carlo evidence and an application to employment equations", Review of Economic Studies 58: 277-97.

Azariadis, C. and J. Stachurski (2004) "Poverty Traps", forthcoming in P. Aghion and S. Durlauf (eds.) Handbook of Economic Growth.

Bardhan, P., S. Bowles, and H. Gintis (2000) "Wealth Inequality, Credit Constraints, and Economic Performance", pp. 541-603 in A.B. Atkinson and F. Bourguignon (eds.) Handbook of Income Distribution, North-Holland: Amsterdam.

Banerjee, A. and A. Newman (1993) "Occupational Choice and the Process of Development", Journal of Political Economy 101(2): 274-298. 
Bound, J., C. Brown, and N. Mathiowetz (2001) "Measurement Error in Survey Data", pp. 3705-3843 in J. Heckman and E. Leamer (eds.), Handbook of Econometrics Volume 5, Elsevier: Amsterdam.

Bound, J., and A. Krueger (1991) "The extent of measurement error in longitudinal earnings data: do two wrongs make a right?", Journal of Labor Economics 12: 345-68.

Bowles, S., S. Durlauf and K. Hoff (2004) Poverty Traps, manuscript in press.

Carter, M. and C. Barrett (2005) "The Economics of Poverty Traps and Persistent Poverty: An Asset-based approach", SAGA Working Paper 178.

Collado, M. Dolores (1997) "Estimating dynamic models from time series of independent cross-sections", Journal of Econometrics 82(1): 37-62.

Dasgupta, P. (1997) "Nutritional Status, the Capacity for Work, and Poverty Traps", Journal of Econometrics 77: 5-37.

Dasgupta, P. and D. Ray (1986) "Inequality as a Determinant of Malnutrition and Unemployment", The Economic Journal Vol. 96, No. 384: 1011-34.

Deaton, A. (1985) "Panel data from time series of cross-sections", Journal of Econometrics 30: 109-126.

Galor, O. and J. Zeira (1993) "Income Distribution and Macroeconomics", Review of Economic Studies 60(1): 35-52.

Ghatak, M., M. Morelli and T. Sjostrom (2001) "Occupational Choice and Dynamic Incentives", Review of Economic Studies 68(4): 781-810.

Jalan, J. and M. Ravallion (2004). "Household Income Dynamics in Rural China", pp. 108-124 in S. Dercon (eds.) Insurance Against Poverty, Oxford University Press: Oxford.

Kniesner, T. and Q. Li (2002). "Nonlinearity in Dynamic Adjustment: Semiparametric Estimation of Panel Labor Supply," Empirical Economics 27:131148.

Lokshin, M. and M. Ravallion (2004) "Household Income Dynamics in Two Transition Economies", Studies in Nonlinear Dynamics and Econometrics 8(3), Article 4. http://www.bepress.com/snde/vol8/iss3/art4. 
Lybbert, T., C. Barrett, S. Desta, and D. Coppock (2004) "Stochastic Wealth Dynamics and Risk Management Among a Poor Population", The Economic Journal 114: 750-777.

McKenzie, D. (2001) "Estimation of AR(1) models with unequally-spaced pseudo-panels", Econometrics Journal, 4: 89- 108

McKenzie, D. (2004) "Asymptotic theory for heterogeneous dynamic pseudopanels", Journal of Econometrics 120(2): 235-262.

McKenzie, D. and C. Woodruff (2003) "Do entry costs provide an empirical basis for poverty traps? Evidence from Mexican microenterprises", BREAD Working Paper No. 020.

Mookherjee, D. and D. Ray (2002) "Contractual Structure and Wealth Accumulation", American Economic Review 92(4): 818-849.

Moffitt, Robert (1993) "Identification and estimation of dynamic models with a time series of repeated cross-sections", Journal of Econometrics 59(1): 99-124.

Strauss, J. and D. Thomas (1998) "Health, Nutrition, and Economic Development", Journal of Economic Literature 36(2): 766-817.

Verbeek, M. and F. Vella (forthcoming) "Estimating dynamic models from repeated cross-sections", Journal of Econometrics. 
Figure 1: Individual Heterogeneity, Non-Convexities and Poverty Traps

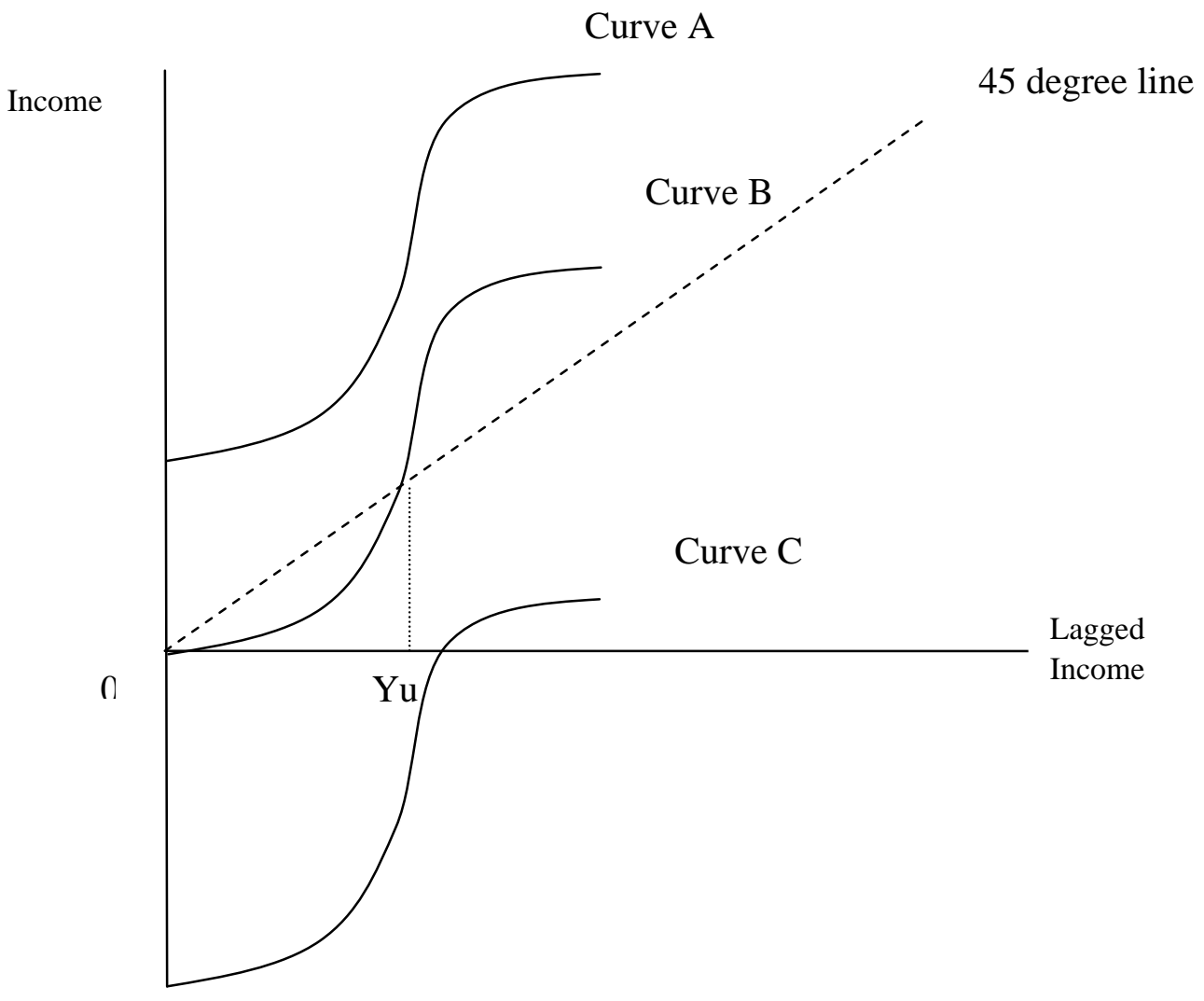

All curves display non-convexities and are simply shifted up or down due to different values of ai. Curve A does not display a poverty trap because it does not intersect the 45 degree line from below. Curve $\mathrm{B}$ demonstrates the case where there is a distinct poverty trap for those below income level Yu. Curve $\mathrm{C}$ is the case where everyone is subject to a poverty trap and is easily verifiable because no one returns to their past income levels. 


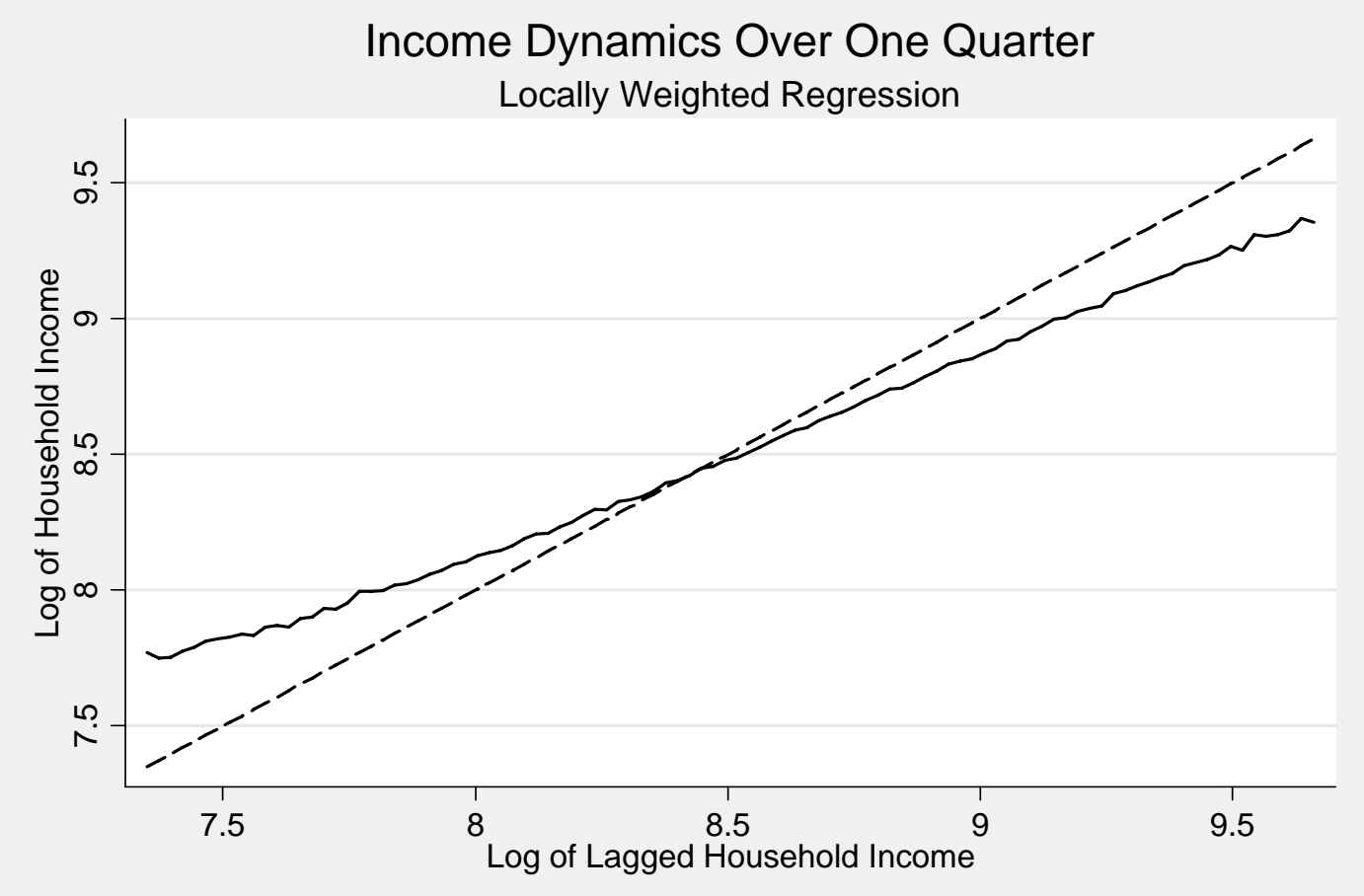

Figure 3

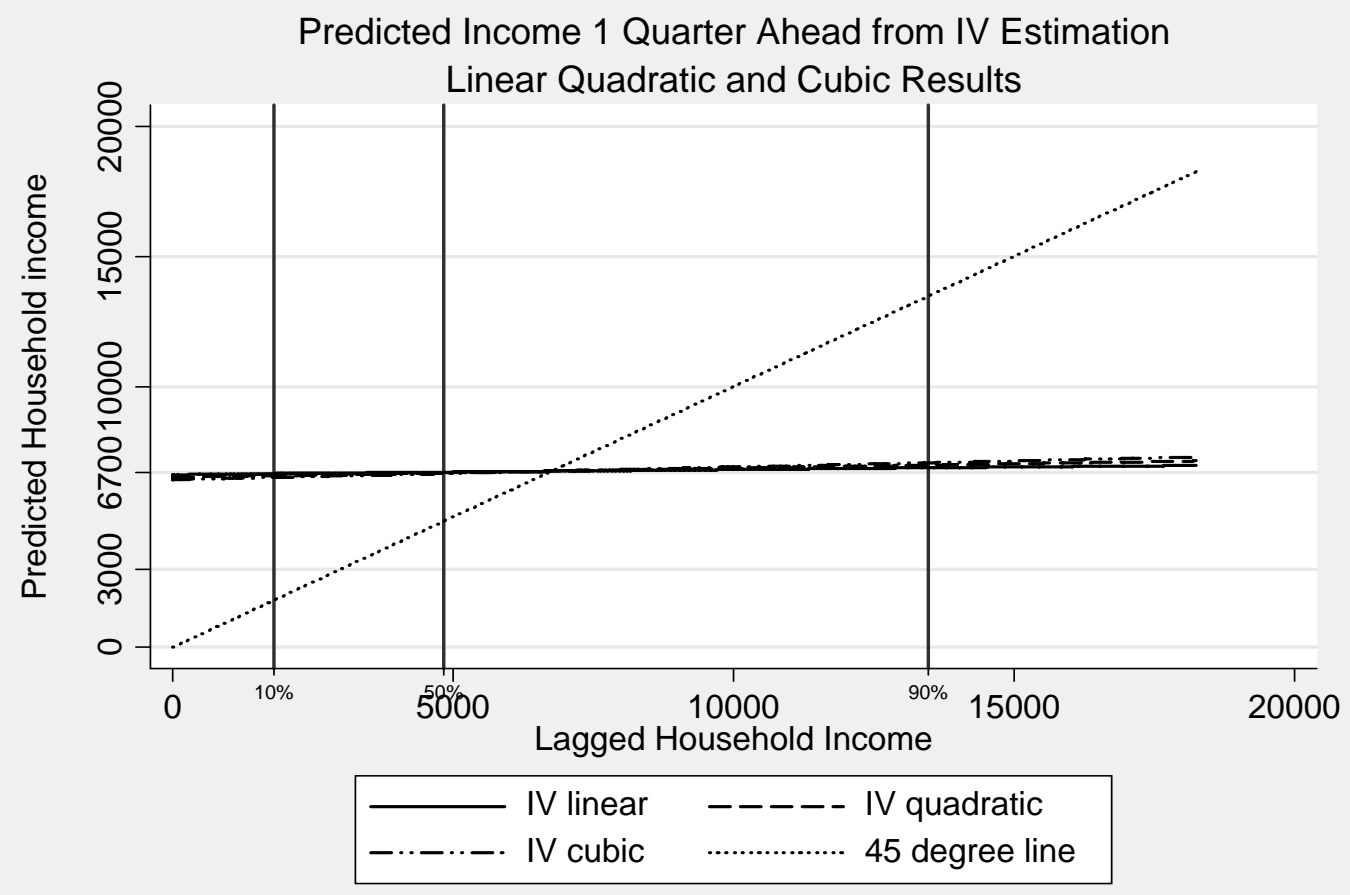




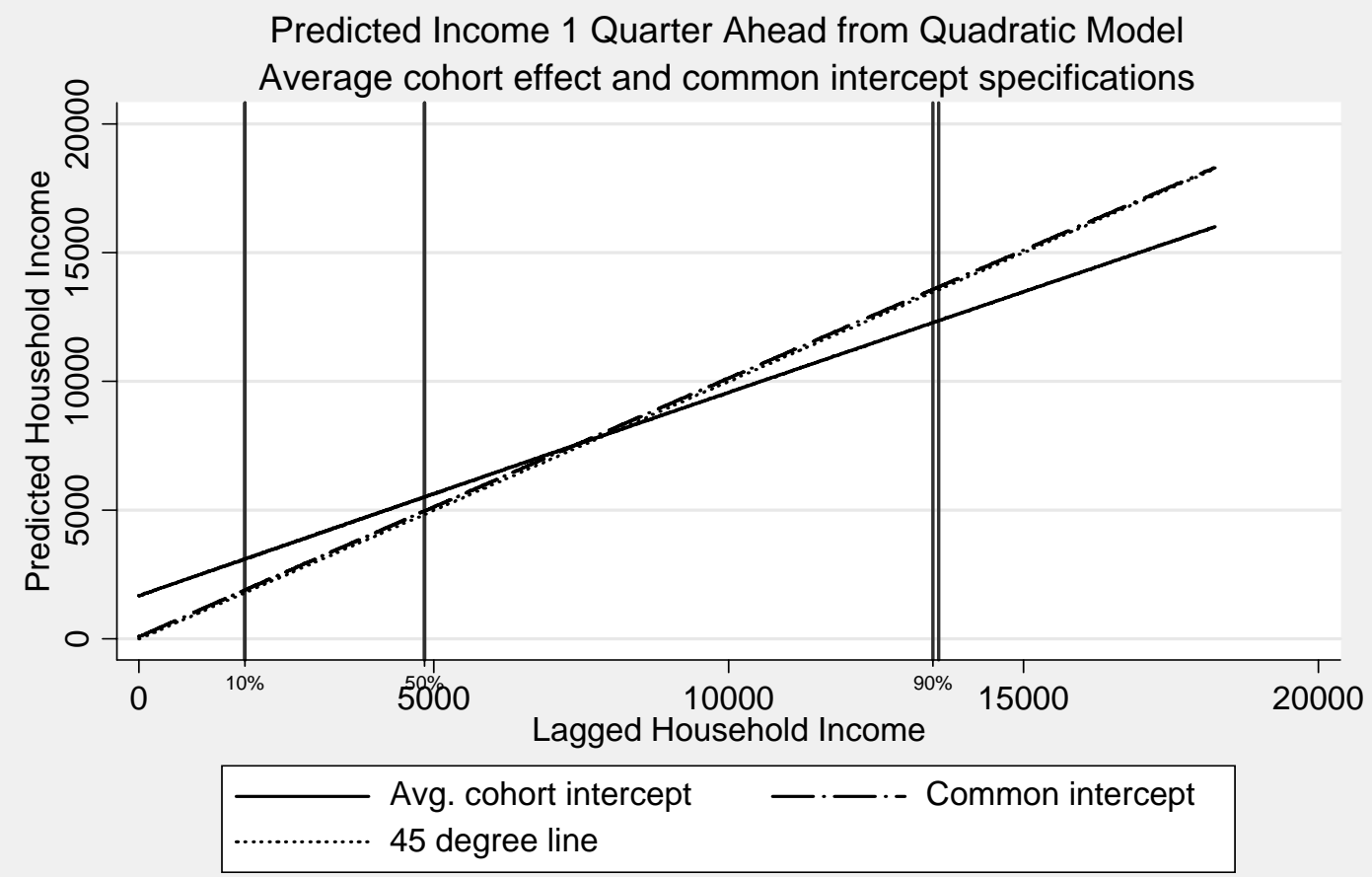

Figure 5

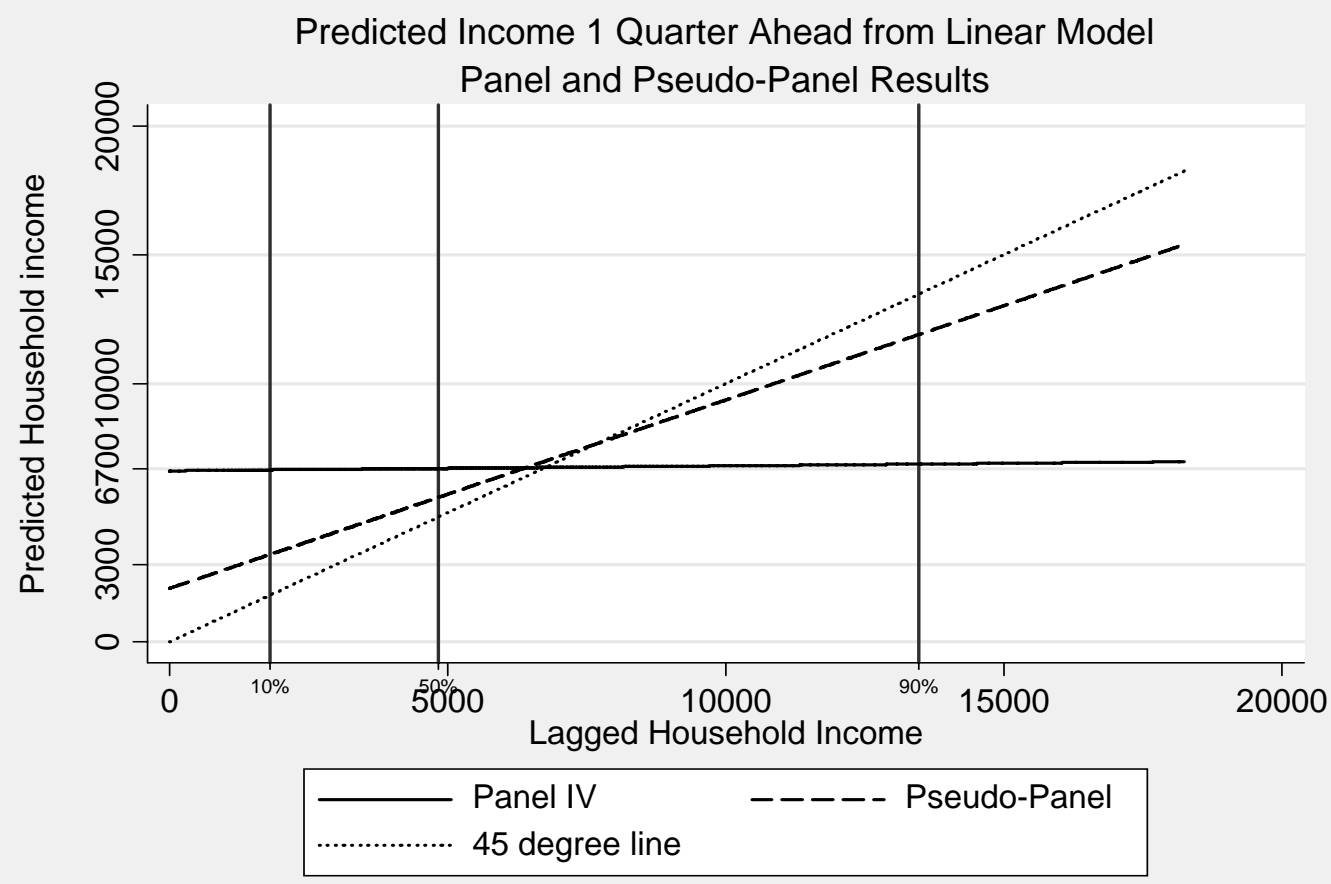




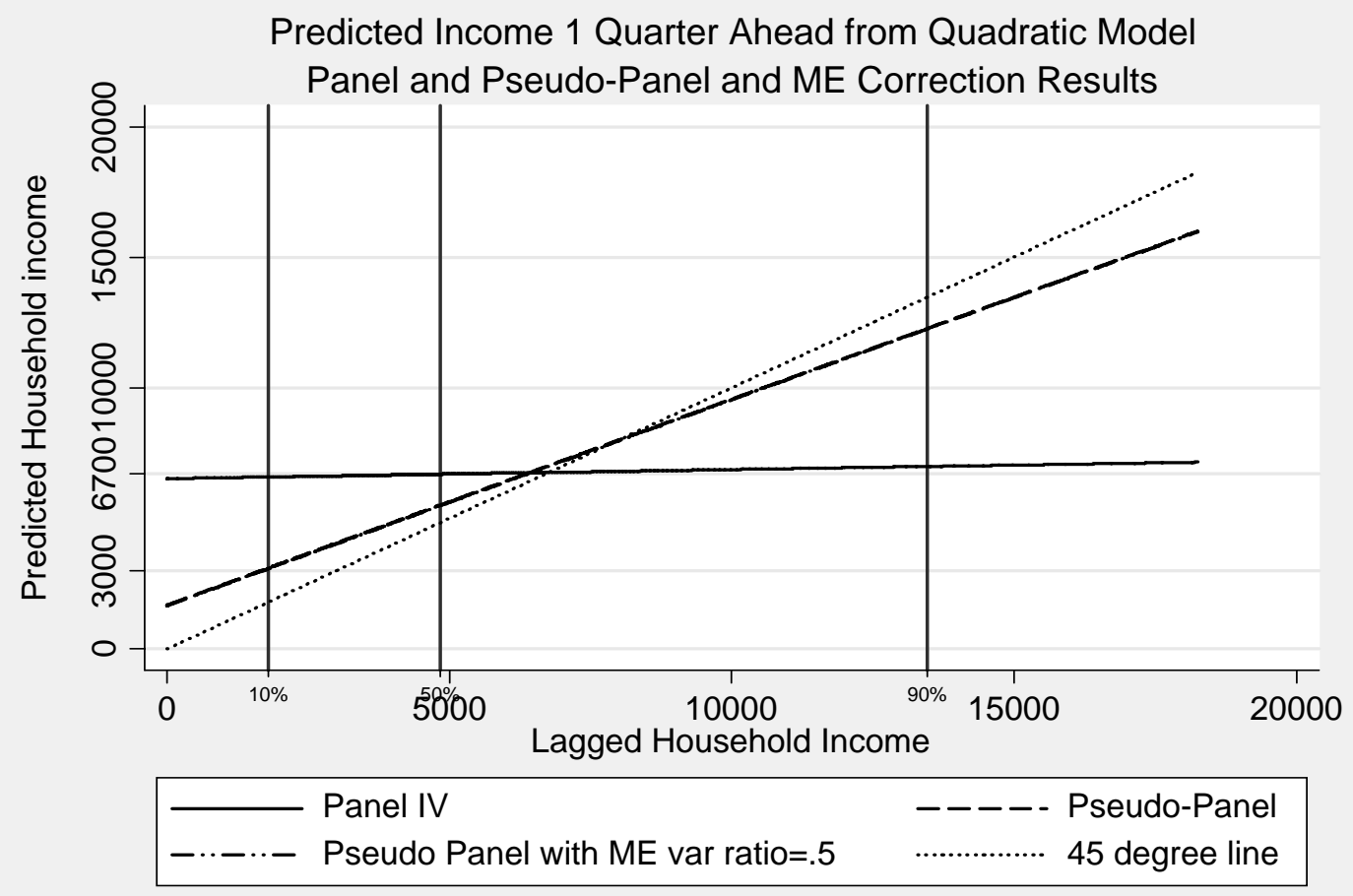

Figure 7

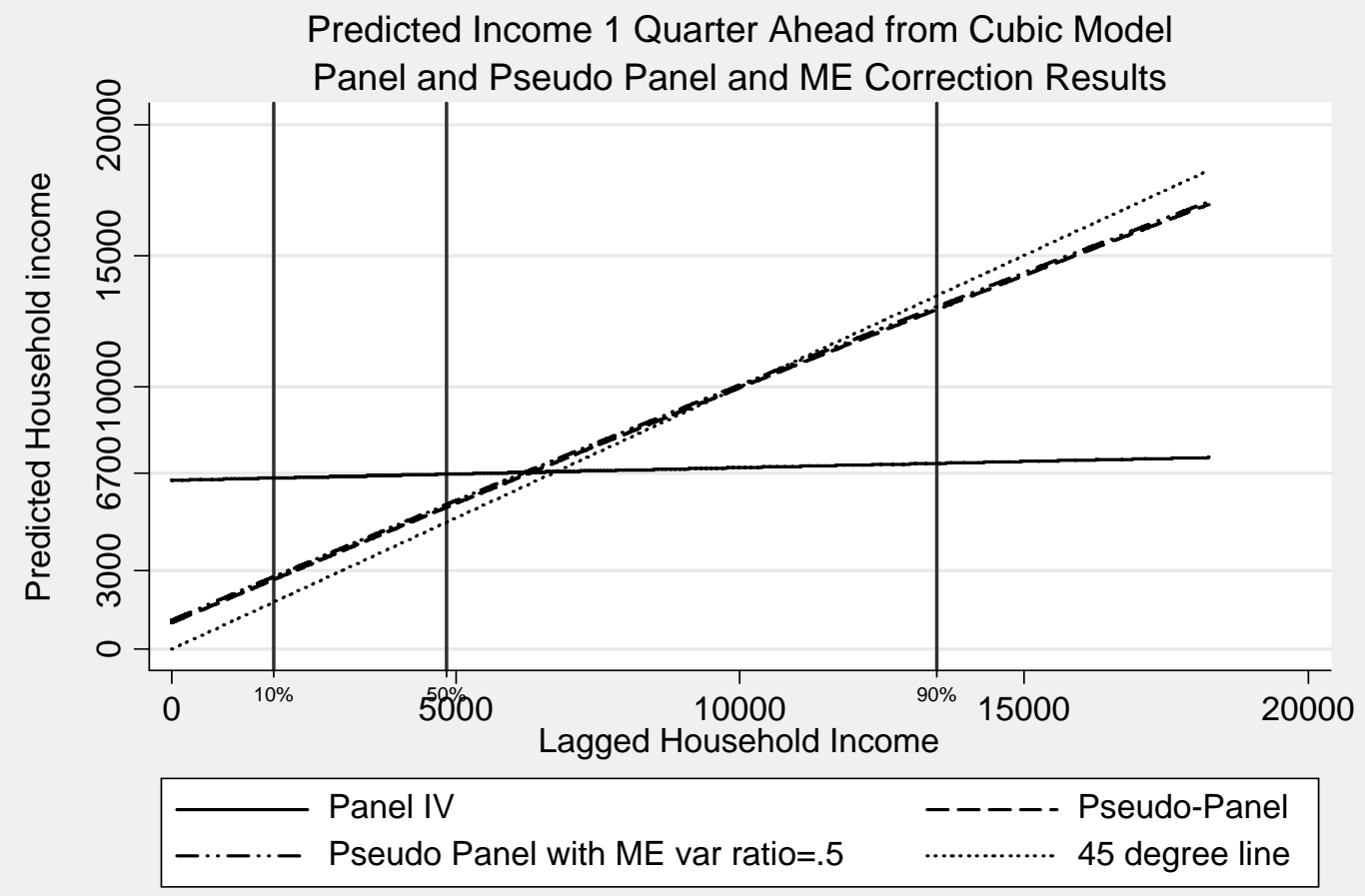




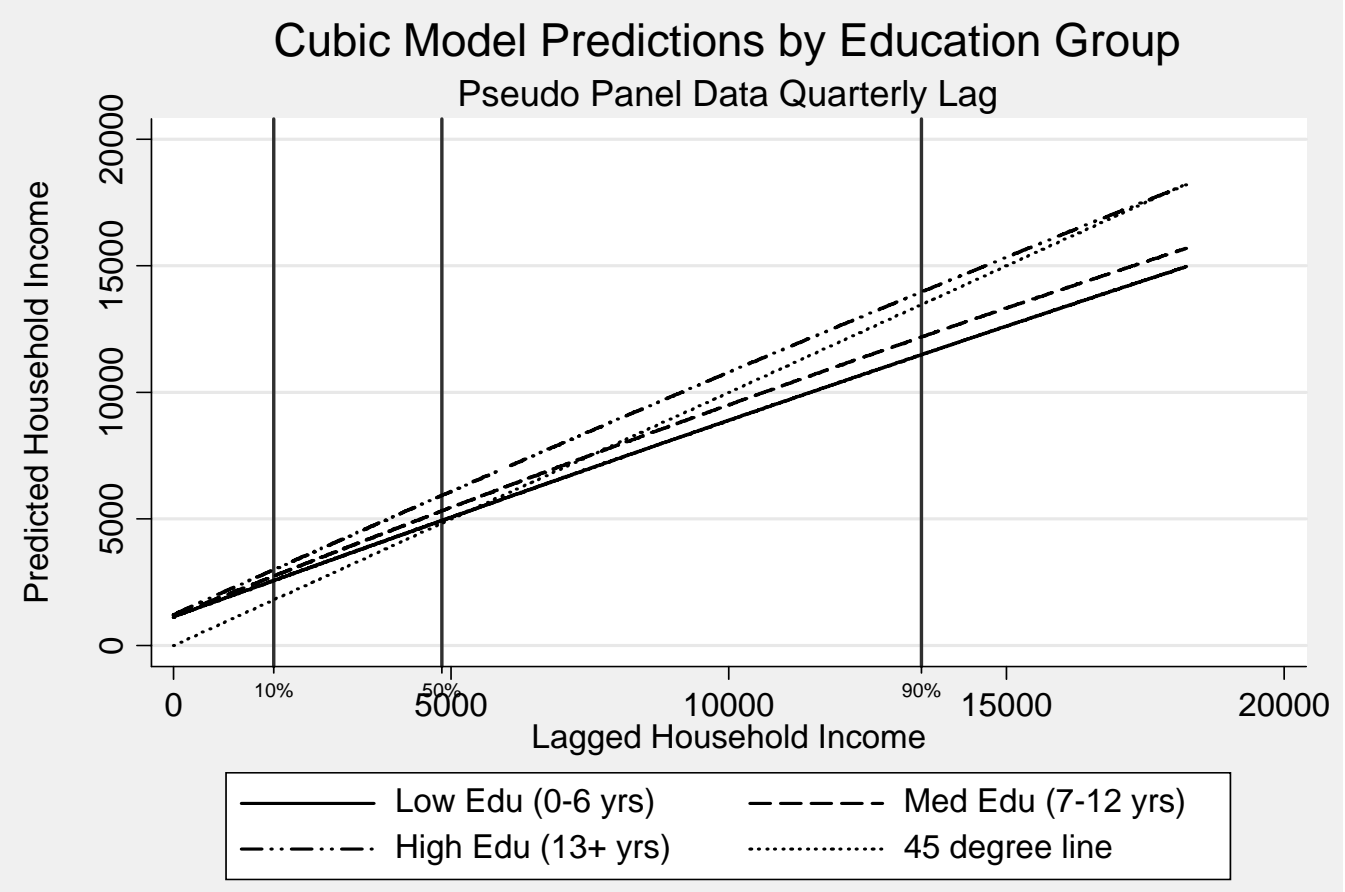

Figure 9

Cubic Model of Income and Expenditure

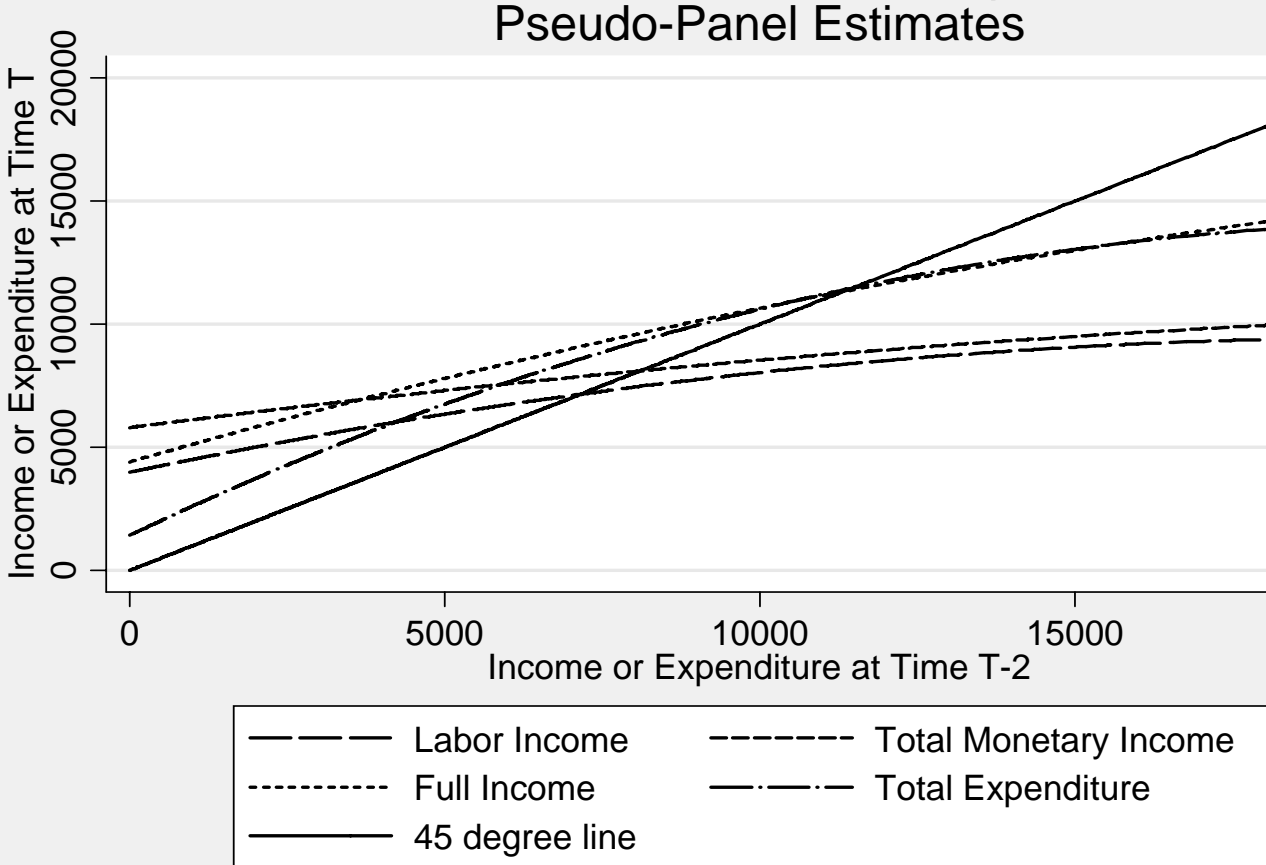




\section{Table 1: Roots and Derivatives from Panel Analysis, Quarterly Lag}

Linear Model

\begin{tabular}{lrr}
\hline & Solution $^{1}$ & \multicolumn{2}{c}{ Derivative $^{2}$} \\
\hline Min & 0 & 0.019 \\
$25 \%$ & 3195 & 0.019 \\
$50 \%$ & 5076 & 0.019 \\
$75 \%$ & 8295 & 0.019 \\
Max & 1381107 & 0.019 \\
\multicolumn{3}{c}{ Quadratic Model } \\
\hline
\end{tabular}

\begin{tabular}{rlrr} 
& & Solution & Derivative \\
\cline { 2 - 4 } Solution 1 & 0 & 0.035 \\
& $25 \%$ & 3195 & 0.035 \\
& $50 \%$ & 5077 & 0.034 \\
& $75 \%$ & 8296 & 0.034 \\
& Max & 1381107 & -0.005 \\
& & & \\
Solution 2 & Solution & Derivative \\
\cline { 2 - 4 } & Min & -68224728 & 2.005 \\
& $25 \%$ & -66851912 & 1.966 \\
& $50 \%$ & -66848696 & 1.966 \\
& $75 \%$ & -66846812 & 1.965 \\
& Max & -66843616 & 1.965 \\
& \multicolumn{3}{c}{ Cubic Model } \\
\cline { 2 - 3 } & \multicolumn{3}{c}{}
\end{tabular}

$\begin{array}{rlrr} & & & \\ & & & \\ & \text { Min } & 7089762.5 & \text { Derivative } \\ \text { Solution 1 } & 25 \% & 7706073 & 3.965 \\ & 50 \% & 7707242.5 & 3.621 \\ & 75 \% & 7707926 & 3.622 \\ & \text { Max } & 7709084.5 & 3.623\end{array}$

\begin{tabular}{llrr} 
& & Solution & Derivative \\
\cline { 2 - 4 } Solution 2 & Min & -5144571.5 & 3.247 \\
& $50 \%$ & -4388072 & 2.496 \\
& $75 \%$ & -4386022.5 & 2.494 \\
& Max & -4384823 & 2.493 \\
& \multicolumn{3}{c}{} \\
\cline { 2 - 4 } Solution 3 3 & Solution & Derivative \\
\cline { 2 - 4 } & Min & 0.02815853 & 0.049 \\
& $25 \%$ & 3195.0723 & 0.049 \\
& $50 \%$ & 5078.0293 & 0.048 \\
& $75 \%$ & 8296.748 & 0.048 \\
& Max & 1381106.8 & -0.048
\end{tabular}

${ }^{1}$ Solution refers to the solution to the equation $Y_{i, t}=\beta_{1} Y_{i, t}+\beta_{2} Y_{i, t}{ }^{2}+\beta_{3} Y_{i, t}{ }^{3}+\alpha_{i}$ where the number of terms in the polynomial correspond to the linear, quadratic and cubic models.

${ }^{2}$ Derivative refers to the derivative of the polynomial evaluated at the solution

${ }^{3} \operatorname{Variance}$ Ratio refers to $\operatorname{Var}\left(\mathrm{Y}_{\mathrm{i}, \mathrm{t}}{ }^{*}\right) / \operatorname{Var}\left(\mathrm{Y}_{\mathrm{i}, \mathrm{t}}\right)$, where * indicates truth 
Table 2: Roots and Derivatives from Pseudo-Panel Analysis, Quarterly Lag

\begin{tabular}{|c|c|c|c|c|c|c|c|c|c|}
\hline & & & & \multicolumn{3}{|c|}{ Linear Model } & & & \\
\hline & & & & \multicolumn{2}{|c|}{ Solution $^{1}$} & Derivative $^{2}$ & & & \\
\hline & & & & Min & 3554 & 0.730 & & & \\
\hline & & & & $25 \%$ & 5312 & 0.730 & & & \\
\hline & & & & $50 \%$ & 6249 & 0.730 & & & \\
\hline & & & & $75 \%$ & 9705 & 0.730 & & & \\
\hline & & & & Max & 18200 & 0.730 & & & \\
\hline & \multicolumn{9}{|c|}{ Quadratic Model } \\
\hline & \multicolumn{3}{|c|}{ No Measurement Error } & \multicolumn{6}{|c|}{ Measurement Error Correction } \\
\hline & & & & \multicolumn{3}{|c|}{ Variance Ratio ${ }^{3}=.8$} & \multicolumn{3}{|c|}{ Variance Ratio $=.5$} \\
\hline & & Solution & Derivative & & Solution & Derivative & & Solution & Derivative \\
\hline & $\overline{M i n}$ & -416471 & 1.226 & $\overline{M i n}$ & -416437 & 1.226 & $\overline{M i n}$ & -416386 & 1.226 \\
\hline & $25 \%$ & -406714 & 1.216 & $25 \%$ & -406678 & 1.216 & $25 \%$ & -406624 & 1.216 \\
\hline \multirow[t]{6}{*}{ Solution 1} & $50 \%$ & -403459 & 1.213 & $50 \%$ & -403423 & 1.213 & $50 \%$ & -403368 & 1.213 \\
\hline & $75 \%$ & -402271 & 1.212 & $75 \%$ & -402234 & 1.212 & $75 \%$ & -402179 & 1.211 \\
\hline & Max & -400502 & 1.210 & Max & -400465 & 1.210 & Max & -400410 & 1.210 \\
\hline & & Solution & Derivative & & Solution & Derivative & & Solution & Derivative \\
\hline & $\overline{M i n}$ & 3636 & 0.790 & $\overline{M i n}$ & 3599 & 0.790 & Min & 3544 & 0.790 \\
\hline & $25 \%$ & 5405 & 0.788 & $25 \%$ & 5368 & 0.788 & $25 \%$ & 5313 & 0.789 \\
\hline \multirow[t]{9}{*}{ Solution 2} & $50 \%$ & 6593 & 0.787 & $50 \%$ & 6557 & 0.787 & $50 \%$ & 6502 & 0.787 \\
\hline & $75 \%$ & 9848 & 0.784 & $75 \%$ & 9812 & 0.784 & $75 \%$ & 9758 & 0.784 \\
\hline & Max & 19605 & 0.774 & Max & 19571 & 0.774 & Max & 19520 & 0.774 \\
\hline & \multicolumn{9}{|c|}{ Cubic Model } \\
\hline & \multicolumn{3}{|c|}{ No Measurement Error } & \multicolumn{6}{|c|}{ Measurement Error Correction } \\
\hline & & & & \multicolumn{3}{|c|}{ Variance Ratio $=.8$} & \multicolumn{3}{|c|}{ Variance Ratio= .5} \\
\hline & & Solution & Derivative & & Solution & Derivative & & Solution & Derivative \\
\hline & Min & 1831966 & 6.228 & Min & 1831958 & 6.228 & Min & 1831947 & 6.228 \\
\hline & $25 \%$ & 1832363 & 6.233 & $25 \%$ & 1832355 & 6.233 & $25 \%$ & 1832343 & 6.232 \\
\hline \multirow[t]{6}{*}{ Solution 1} & $50 \%$ & 1832461 & 6.234 & $50 \%$ & 1832453 & 6.234 & $50 \%$ & 1832441 & 6.234 \\
\hline & $75 \%$ & 1832491 & 6.234 & $75 \%$ & 1832484 & 6.234 & $75 \%$ & 1832472 & 6.234 \\
\hline & Max & 1832534 & 6.235 & Max & 1832526 & 6.234 & Max & 1832514 & 6.234 \\
\hline & & Solution & Derivative & & Solution & Derivative & & Solution & Derivative \\
\hline & Min & -49921 & 1.213 & Min & -50114 & 1.214 & Min & -50402 & 1.215 \\
\hline & $25 \%$ & -38242 & 1.143 & $25 \%$ & -38528 & 1.145 & $25 \%$ & -38951 & 1.147 \\
\hline \multirow[t]{6}{*}{ Solution 2} & $50 \%$ & -34352 & 1.120 & $50 \%$ & -34692 & 1.122 & $50 \%$ & -35192 & 1.125 \\
\hline & $75 \%$ & -32960 & 1.112 & $75 \%$ & -33324 & 1.114 & $75 \%$ & -33859 & 1.117 \\
\hline & Max & -30870 & 1.100 & Max & -31278 & 1.102 & Max & -31873 & 1.106 \\
\hline & & Solution & Derivative & & Solution & Derivative & & Solution & Derivative \\
\hline & Min & 3965 & 0.902 & $\overline{M i n}$ & 4381 & 0.900 & $\overline{M i n}$ & 4988 & 0.897 \\
\hline & $25 \%$ & 6098 & 0.890 & $25 \%$ & 6470 & 0.888 & $25 \%$ & 7017 & 0.885 \\
\hline \multirow[t]{3}{*}{ Solution 3} & $50 \%$ & 7521 & 0.883 & $50 \%$ & 7869 & 0.881 & $50 \%$ & 8381 & 0.878 \\
\hline & $75 \%$ & 11508 & 0.861 & $75 \%$ & 11802 & 0.859 & $75 \%$ & 12238 & 0.857 \\
\hline & Max & 23584 & 0.796 & Max & 23785 & 0.795 & Max & 24085 & 0.793 \\
\hline
\end{tabular}

${ }^{1}$ Solution refers to the solution to the equation $Y_{i, t}=\beta_{1} Y_{i, t}+\beta_{2} Y_{i, t}{ }^{2}+\beta_{3} Y_{i, t}{ }^{3}+\alpha_{c}$, where the number of terms in the polynomial correspond to the linear, quadratic and cubic models.

${ }^{2}$ Derivative refers to the derivative of the polynomial evaluated at the solution

${ }^{3} \operatorname{Variance}$ Ratio refers to $\operatorname{Var}\left(\mathrm{Y}_{\mathrm{i}, \mathrm{t}}{ }^{*}\right) / \operatorname{Var}\left(\mathrm{Y}_{\mathrm{i}, \mathrm{t}}\right)$, where * indicates truth 